\title{
Marx para além da grande-indústria
}

\author{
Daniel Romero
}

\section{APRESEnTAÇ̃̃o}

As profundas transformações atuais no mundo do trabalho têm sugerido a superação do capitalismo de tipo industrial para formas sociais de produção mais baseadas no uso da informação, no trabalho imaterial e na relação entre ciência e processo de produção. Tais transformações, inclusive, serviram de suporte para a idéia de que estaríamos rumo a sociedades de tipo "pós-industrial".

Para alguns estudiosos, é como se estivéssemos diante não apenas de mutações fenomênicas e particulares, mas da reconfiguração das próprias bases da sociedade atual $^{2}$. Nos casos mais extremos, estas mudanças indicariam a formação de um novo projeto civilizacional e a exigência de uma radical mudança epistemológica visando a construção de uma nova teoria dos conflitos ${ }^{3}$. Como ressalta Mandel, "a presente crise não é vista como uma crise típica de superprodução e superacumulação, mas como uma

1 Doutorando em Ciências Sociais pela Unicamp.

2 Robert Kurz, 0 Colapso da Modernização. Rio de Janeiro, Paz e Terra, 1993; Jean Lojkine, A Revolução Informacional. São Paulo, Cortez, 1995; Jean-Marie Vincent, "Os Automatismos Sociais e o “General Intellect”, In: J. Bidet \& J. Texier, La Crise du Travail. Paris, PUF, 1995; Adam Schaff, A Sociedade Informática. São Paulo, Ed. Unesp/Ed. Brasiliense, 1992.

3 Jürgen Habermas, “Técnica e Ciência como 'Ideologia' “, In: Os Pensadores. São Paulo, Abril Cultural, 1975, vol. XLVIII, pp. 303-333.

cadernos cemarx, $n^{0} 2-2005 \quad \mathbf{4 5}$ 
crise de civilização" ". Este também é o caso de teóricos que tematizam o "fim da sociedade do trabalho"s.

A presente pesquisa visa poder contribuir para este extenso debate em torno das transformações atuais no mundo do trabalho e acreditamos que isto pode ser feito pelo retorno à "letra" de Marx. Esta comunicação se propõe a discutir a relação entre ciência e processo de produção nos Grundrisse de Karl Marx. A nossa proposta principal é ler a teoria da transição de Marx presente na referida obra como uma possível indicação de uma teoria da pós-grande indústria (nos termos de Ruy Fausto ${ }^{6}$ ) ainda nos marcos do modo de produção capitalista. Ou seja, como uma terceira forma social de produção capitalista, para além da manufatura e da grande indústria.

Nesta obra, o autor aborda questões que acreditamos ser de extrema pertinência para a análise do processo de produção, como a interação entre trabalho e saber científico. A partir disto, esta comunicação é um esforço inicial de precisar e atualizar alguns conceitos como o de divisão do trabalho e subsunção, o que permitiria avançar numa teoria capitalista da pós-grande indústria.

\section{DIVISÃO DO TRABALHO E SUBSUNÇ̃̃O NA PÓS-GRANDE INDÚSTRIA}

Nos Grundrisse, Marx procura analisar o desenvolvimento da grande indústria a partir das transformações materiais do processo de produção e das contradições advindas destas transformações. As contradições que Marx assinala neste texto seriam em função da substituição de trabalho vivo pelo trabalho morto, como "(...) o último desenvolvimento sobre a relação de valor e da produção apoiada sobre o valor" . Como nos referimos anteriormente, estas passagens dos Grundrisse podem nos fornecer indicações acerca de uma terceira forma social de produção de tipo capitalista, que tende a superar a grande indústria.

$-\cdots-\cdots$

4 Ernest Mandel, "Marx, La Crise Actuelle et L'avenir du Travail Humain" in: Quatrieme Internationale, no 20, 1986, p. 01 (mimeo).

5 Clauss Offe, "Trabalho como Categoria Sociológica Fundamental?", In: Trabalho e Sociedade. Vol. I - A Crise. Rio de Janeiro, Tempo Brasileiro, 1989; André Gorz, Adeus ao Proletariado. Rio de Janeiro, Ed. Forense-Universitária, 1982.

6 Ruy Fausto, Marx: Lógica e Política. São Paulo, Editora 34, Tomo III, 2003.

7 Karl Marx, "Contradição entre o fundamento da produção burguesa (medida-valor) e seu próprio desenvolvimento", In: José Arthur Giannotti, Marx - Vida e Obra. Porto Alegre, L\&PM, 2000, pp. 183-188, p. 184.

46 Marx para além da grande-indústria 
Segundo Marx, a primeira transformação importante da base material advinda do desenvolvimento da grande indústria, e que seria um processo inicial de sua superação, seria a tendência de supressão do trabalho imediato como elemento determinante da produção.

Com o desenvolvimento da grande indústria, a produção da riqueza se autonomiza cada vez mais do trabalho imediato e depende do estado geral da ciência, ou seja, de um trabalho de outro tipo, o científico. Neste sentido, é importante precisar o que Marx entende por trabalho imediato e pela supressão do mesmo, para compreendermos as transformações em curso.

Segundo Marx,

o princípio desenvolvido do capital é precisamente tornar supérfluo o trabalho manual, o trabalho corporal direto, tanto em qualidade de trabalho habilidoso como em qualidade de esforço muscular; colocar a destreza nas inanimadas forças naturais ${ }^{8}$.

Poder-se-ia dizer que Marx entende por supressão do trabalho imediato simplesmente a substituição de trabalho vivo por trabalho morto. Contudo, além desta mudança, pode-se encontrar também uma mudança qualitativa ${ }^{9}$. Neste caso, não é mais o trabalho que está sendo suprimido, mas o seu caráter imediato; o trabalho está sendo transformado em "pura abstração da atividade" laboral.

Com o desenvolvimento da indústria, o capital tende a dar um caráter científico à produção e, com isso, o trabalho assume uma posição intermediária na mesma, como simples apêndice do processo de trabalho, como intermediário entre a máquina e o objeto transformado; é em função desta posição intermediária que o trabalho deixa de ser o sujeito do processo de produção. Contudo, isto já existe desde a grande indústria, na medida em que "o processo de produção tem deixado de ser processo de trabalho no sentido de ser controlado pelo trabalho como unidade dominante"10.

A diferença da pós-grande indústria consiste numa nova alteração da posição do $-{ }_{-}-{ }_{-}-{ }_{-}$

8 Karl Marx, Elementos Fundamentales para la Critica de la Economia Politica (Grundrisse) 1857-1858. México, Siglo XXI (vol. II), 1997, p. 89.

9 Cf. Jacques Texier, “La Suppression du Travail Immédiat comme Facteur Décisif de la Production dans le Grundrisse de K. Marx" in: Actuel Marx, n 14, 1993, pp. 135-161.

10 Karl Marx, Elementos Fundamentales para la Critica de la Economia Politica (Grundrisse) 1857-1858, cit., p. 219.

cadernos cemarx, $n^{0} 2-2005 \quad \mathbf{4 7}$ 
trabalho para além de sua posição intermediária, quando começa a assumir atividades de supervisão e controle, que negaria a reificação social operada pela grande indústria, ou seja, a inversão entre sujeito e objeto, reconfigurando a divisão do trabalho da fase do maquinismo.

Segundo Fausto, "se a grande indústria aparece como a negação do processo de trabalho, a pós-grande indústria é a segunda negação do processo de trabalho, e na realidade a negação da negação" ${ }^{\prime 1}$. Esta negação da negação mudaria a posição do trabalho no processo de produção, desenvolveria uma nova divisão do trabalho, restabeleceria o caráter subjetivo da organização do processo de trabalho e reconfiguraria a imagem do sujeito do processo de produção, mas de um processo de produção distinto daquele da grande indústria:

[O trabalhador] comparece ao lado do processo de produção em vez de ser seu agente principal. Nessa transformação, não é nem o trabalho imediato, executado pelo próprio homem, nem o tempo que ele trabalha, mas a apropriação de sua força produtiva geral, seu entendimento e dominação da natureza por meio de sua existência como corpo social - numa palavra, o desenvolvimento do indivíduo social é o que aparece como o pilar fundador da produção e da riqueza ${ }^{12}$.

Cabe, neste sentido, ressaltar que Marx prevê modificações na divisão do trabalho durante a pós-grande indústria, bem como uma nova posição do trabalho e a retomada do princípio subjetivo da organização do processo de produção. A pós-grande indústria não consiste numa abolição do trabalho em direção a uma automação total e, mesmo que haja algumas semelhanças, também não é o caso de um retorno a divisões do trabalho de fases pré-industriais. Significa uma nova forma de divisão do trabalho, correspondente a uma também nova forma social de produção, resultante de um processo de abolição e conservação do trabalho, como sugere Texier:

Há, por um lado, uma supressão-conservação do trabalho vivo que, sob a forma de uma atividade puramente abstrata de supervisão (socialmente combi-

$---\cdots$

11 Fausto, op. cit, p. 49.

12 Karl Marx, "Contradição entre o fundamento da produção burguesa (medida-valor) e seu próprio desenvolvimento", cit., 184.

48 Marx para além da grande-indústria 
nada) do operário, continua como um momento necessário do processo de produção e, por outro lado, uma supressão-abolição do trabalho vivo como fator decisivo da produção. Ele é substituído neste caso pelo trabalho científico e tecnológico que se torna o pilar fundamental ou a fonte essencial da riqueza ${ }^{13}$.

Neste sentido, há que se discutir em que medida a pós-grande indústria supera e conserva a subsunção do trabalho da grande indústria. Haveria uma subsunção própria da pós-grande indústria, que superaria a subsunção real do trabalho ao capital? Embora em nenhum momento isso fique explícito em Marx, acreditamos que a resposta a esta indagação seja afirmativa. Com a alteração na divisão do trabalho própria da grande indústria, em função do processo de produção voltar a ser organizado sob um princípio subjetivo, também se altera a alienação do trabalho. A chave desta resposta se encontra na análise da relação entre a base material da pós-grande indústria e a forma social capitalista.

O maquinismo é a base material adequada à forma social capitalista, porque ele permite o aumento da extração da mais-valia por meio da mais-valia relativa e, ao mesmo tempo, um aumento do controle do capital sobre o processo de trabalho. Existe, portanto, uma adequação entre a base material e a forma social, que supera a fase da manufatura cuja base artesanal era inadequada ao aumento da extração de mais-valia relativa e ao controle do capital sobre o processo de produção.

Com o desenvolvimento da indústria, assiste-se a uma nova mudança da base material. É como se ela estivesse "adequada em excesso", porque "o capital, que era uma alma apetitiva (ele tem fome devoradora de trabalho alheio), se apossa de um intelecto, mas acaba sendo dominado por ele"14.

Na primeira forma social de produção capitalista, a manufatura, o trabalhador é o suporte dos instrumentos de trabalho; na segunda forma, a grande indústria, o trabalhador é o apêndice, e na terceira forma, o trabalhador, além de suporte, é servidor dos instrumentos de trabalho ${ }^{15}$. Com isso temos o fim da subsunção real? Sim e não.

A subsunção de tipo real é superada, mas isso não significa que a subsunção terminou, mas que ela agora tem outro caráter. Com a expansão da dimensão intelectual

$-\cdots-\cdots$

13 Texier, op. cit., p. 144

14 Fausto, op. cit., p. 59

15 Idem, ibidem, p. 61.

cadernos cemarx, $n^{0}-2-2005 \quad 49$ 
do trabalho e a retomada do saber-fazer e, principalmente, com a expansão do trabalho imaterial, temos uma subsunção do trabalho que "volta" a ser formal, pois o capital não impõe mais seu controle por meio de uma base material adequada.

A pós-grande indústria estaria desenvolvendo, neste sentido, um sistema de produção no qual o trabalhador poderia ser materialmente livre diante do instrumento de trabalho. Contudo, dentro da lógica do valor, esta liberação seria unicamente em relação à base material, mas não uma liberação da forma social. Fausto sugere o exemplo de um trabalhador que perfaz uma longa jornada trabalhando com um computador ${ }^{16}$. Concretamente, o indivíduo se coloca como elemento ativo deste processo de trabalho. Trata-se de disciplinar o trabalho intelectual, mas não de suprimi-lo; com isso, exigem-se outras formas de disciplinar a força de trabalho, quer por meio da cooptação da subjetividade do trabalhador ("consentimento positivo"), quer por meio da difusão do temor do desemprego (um "consentimento negativo").

Fausto sugere - ou, como ele diz, arrisca - uma nova conceituação desta relação. É como se tivéssemos uma subsunção formal-intelectual do trabalho ao capital ${ }^{17}$. Essa subsunção pode ser ainda mais radical que as anteriores, porque ela é obtida pela introjeção da dominação do capital. Se a subsunção real advinha da relação do trabalhador com os meios de produção, de uma reificação entre sujeito e objeto, e o objeto é que impunha uma forma de dominação sobre o trabalhador ao se tornar sujeito do processo de produção, agora a "subsunção formal-intelectual" não se fundamenta mais nesta relação. Não significa que o objeto some, mas que ele não é mais o fundamento do processo de subsunção.

A subsunção deixa de ter uma base material, pois ela é introjetada pelo trabalhador por meio do envolvimento do mesmo com a empresa. Uma vez que a subsunção se "desmaterializa", a "subsunção formal-intelectual" consiste num processo de autoalienação do trabalho ao capital. Não é mais o caso de suprimir o saber-fazer do trabalhador, mas de ampliá-lo até certo ponto, visando a continuidade do processo de produção. É o trabalhador como parceiro da empresa, que implica o desenvolvimento de uma subjetividade inautêntica ${ }^{18}$.

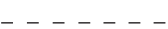

16 Idem, ibidem, p. 61.

17 Idem, ibidem, p. 61.

18 Ricardo Antunes, Os Sentidos do Trabalho. São Paulo, Boitempo, 1999, p. 128.

50 Marx para além da grande-indústria 